\title{
APROXIMACIÓN AL MITO
}

\section{Patricio Oyaneder JARA*}

RESUMEN

Se propone entender "mito" como "narración verdadera", aceptada como tal por quien "vive" el mito, por quien lo "siente" como verdadero. Su función es entregar un fondo al hombre, un conjunto de puntos de referencia que le permiten guiar su vida, entender la realidad y comprenderse a sí mismo en ella. Los mitos arcaicos narran una historia religiosa; pero no todos los mitos son religiosos. Los mitos cambian en el tiempo. En diversos momentos de la historia hay mitos dominantes. Articular mitos otorga poder. Cuando desaparecen los "grandes mitos" su lugar es ocupado por otros de tono menor, que - a falta de otra cosa- igual guían al individuo. Hoy, en nuestra nación carecemos de mitos que involucren a la total idad, tenemos sólo los mitos de la globalización: la democracia y el mercado. Conviene reconocer los mitos, y a la vez, reconocer también que parte de nuestro juicio se afinca en aquellos mitos que nos sustentan.

Palabras daves: Grandes mitos, historia, "narración verdadera", sentido.

\section{ABSTRACT}

We propose to understand "myth" as a "true narration", accepted as such by those who "live" the myth, by those who "feel" it as true. Its function is to provide a foundation for men and women, a set of reference points that will permit them to guide their lives, to understand reality and understand themselves within this reality. The archaic myths narrate a religious story; but not all myths are religious. M yths change over time. In different moments of history there are dominant myths. To articulate myths grants power. When the "great myths" disappear, their place is occupied by others of a minor tone, that -for want of anything else-continue to guide the individual. Today in our nation we lack myths that name a totality, we have only myths of globalization: democracy and the market. It is useful to recognize myths while at the sametime recognizing that part of our judgement is based on those myths that sustain us.

Keywords: Great myths, history, "true narration", sense.

Recibido: 30.01.2003. Aprobado: 05.03.2003.

*Doctor en Filosofíay Letras, profesor en laUniversidad deConcepción. E-mail: poyanede@udec.cl 
L HABLAR SOBRE el mito, lo primero que conviene precisar es el sentido en el que se usará el concepto; en el caso presente, deseo diferenciarlo de su sentido cotidiano, según el cual "mito" es sinónimo de "falsedad", o de "fábula" en el mejor de los casos. Por el contrario, propongo aceptar por valedera la definición demito queentrega Giambattista Vico, la cual, aunque etimológicamente falsa, según dicen los filólogos, resulta esclarecedora: él propone que la voz mythos - refiriéndose principalmente al mito arcaico- significa "narración verdadera"1, esto es, que el relato mítico secaracteriza por ser aceptado como verdadero por quien participa del mismo. Por cierto, este aceptar como verdadero lo relatado no es un asentimiento a un discurso queaparezca como formalmenteválido desdeel punto de vista lógico, sino es una aceptación de una "verdad" sentida como tal como hacen notar los estudiosos contemporáneos- y que por ello permite orientar el propio existir².

Y topamos aquí con la función del mito: entregar al individuo una visión acerca de las cosas y de sí mismo. Una visión tal es necesaria para el hombre en la medida en que le entrega la orientación de la cual, en su origen, carece, puesto que el hombre -y sigo en esto a Luis Cencillo- se nos presenta como desfondado, es decir, carente de una baseuniversal y fija, dada por naturaleza, que le permita conducir su vida de modo unívoco a nivel de especie $e^{3}$. El resto de los animales tiene esa base naturalmente dada en el instinto, el cual les permite actuar -a cada uno- del mismo modo que los demás individuos de su especie ante situaciones similares. El hombre, carente -como he dicho- de aquella base, desfondado, debe creársela, lo que logra construyendo su cultura. Así, el hombre no se afinca en la mera naturaleza sino en su mundo cultural, en el cual dota de sentido a la realidad natural, elabora una imagen desí mismo acorde con dicha realidad, y obtiene así un fondo elaborado por él, que le permite saber a qué atenerse.

En este panorama, el mito es, en su origen, el resultado de los esfuerzos de la humanidad primigenia para formalizar la realidad como un todo coherente con un sentido determinado. El mito nace, de este modo, señalado por su función esencial: dar respuestas respecto de lo quelas cosas y el hombreson.

Esta primera respuesta, en el mito arcaico -tanto en los tiempos históricos cuanto en las culturas primitivas contemporáneas- es religiosa (o cuando menos, mágico-religiosa): el mito versa sobre los comienzos de lo existente, en los cuales la realidad se dispuso de un modo determinado por ac-

'Vico, G., "Scienza nuova", en O pere filosofiche, Sansoni Ed., Firenze, 1971, p. 622. Cf.: Eliade, M., M ito y realidad, M adrid, Guadarrama, 1973, p. 20 ss.

${ }^{2}$ En este sentido, poco importa la verdad objetiva del mito: un mito puedeformarse a partir de algo objetivamente falso. Y también al go objetivamente verdadero puede transformarse en mito, si reclama nuestro sentir como fundamento de nuestro asentir.

${ }^{3}$ Cencillo, L., Tratado de la intimidad y de los saberes, Sintagma, Madrid, 1971, p. 257 ss. 


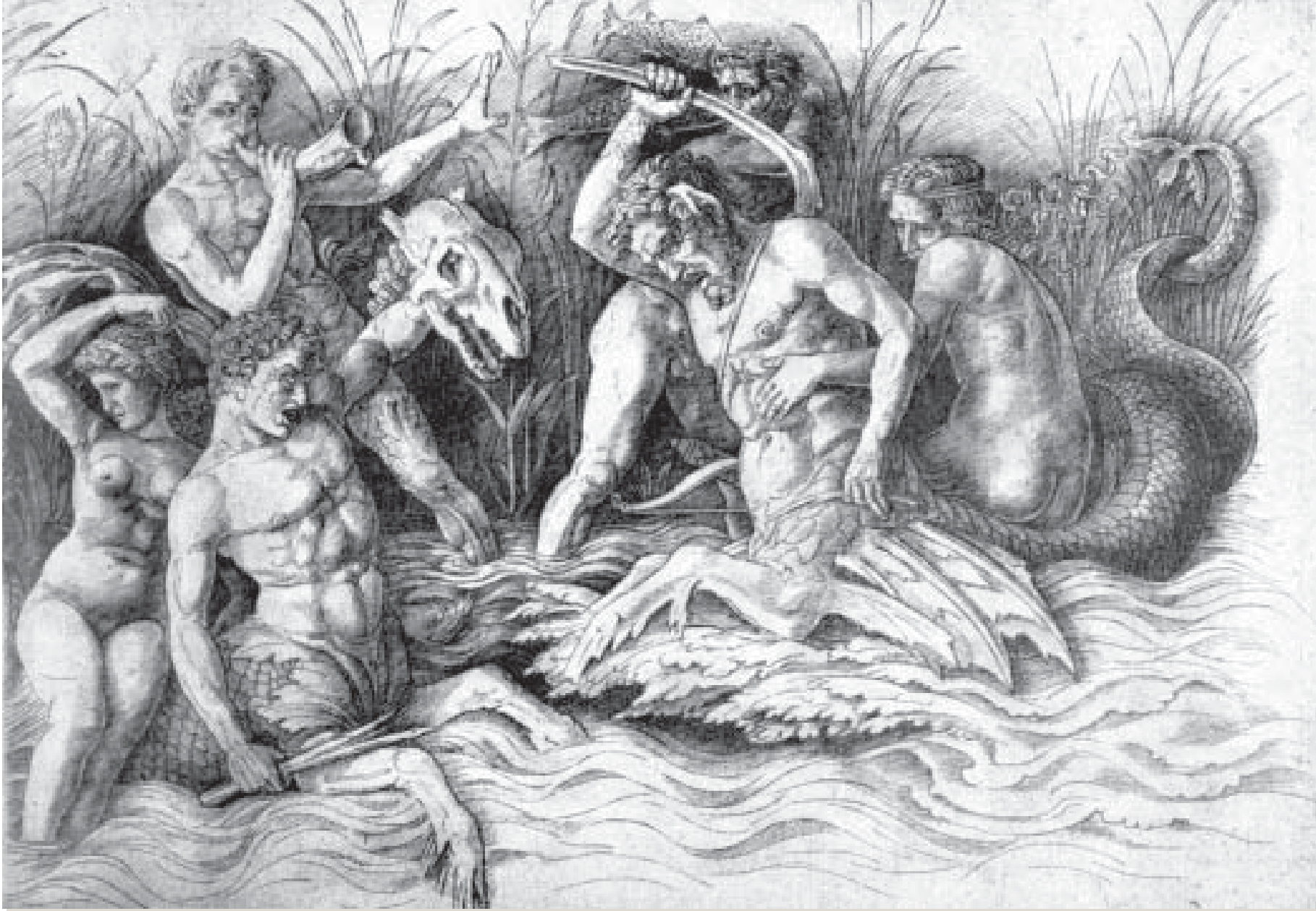

Lucha de divinidades marinas, grabado en madera de Andrea M antegna.

ción de seres superiores, y conocer dicho orden le permite al individuo situarse adecuadamente en él ${ }^{4}$.

Pero - hablo de la cultura occidental ahora- si en los primeros tiempos históricos el mito es relato religioso, pronto sufrió los embates de la crítica racionalista ${ }^{5}$ y como consecuencia de ella la veracidad de su relato fuenegada: el mito sólo narraba historias ficticias. Incluso hubo intentos de explicar el origen de aquellas ficciones, tal como el evemerismo, que consideraba los mitos-cuando menos, aquellos quehablaban de héroes y otros semidiosessí como historia de personajes reales, pero desvirtuada en el tiempo por acción de agregados fabulosos. En el fondo, este tipo de opiniones prescindía del valor simbólico del relato mítico. Por lo demás, también desde antiguo se apreció que intentar rastrear, desde un punto de vista racional, el origen concreto de al gún mito en particular era una tarea imposible ${ }^{6}$.

${ }^{4}$ Vid. Eliade, op. cit., p. 19.

${ }^{5}$ Vid. Cassirer, E., El mito del Estado, Fondo de Cultura Económica, M éxico, 1982, p. 68.

${ }^{6} \mathrm{Cf}$.: Sócrates respecto del rapto de Oreitia por Bóreas, en Fedro, 229c, ss. 


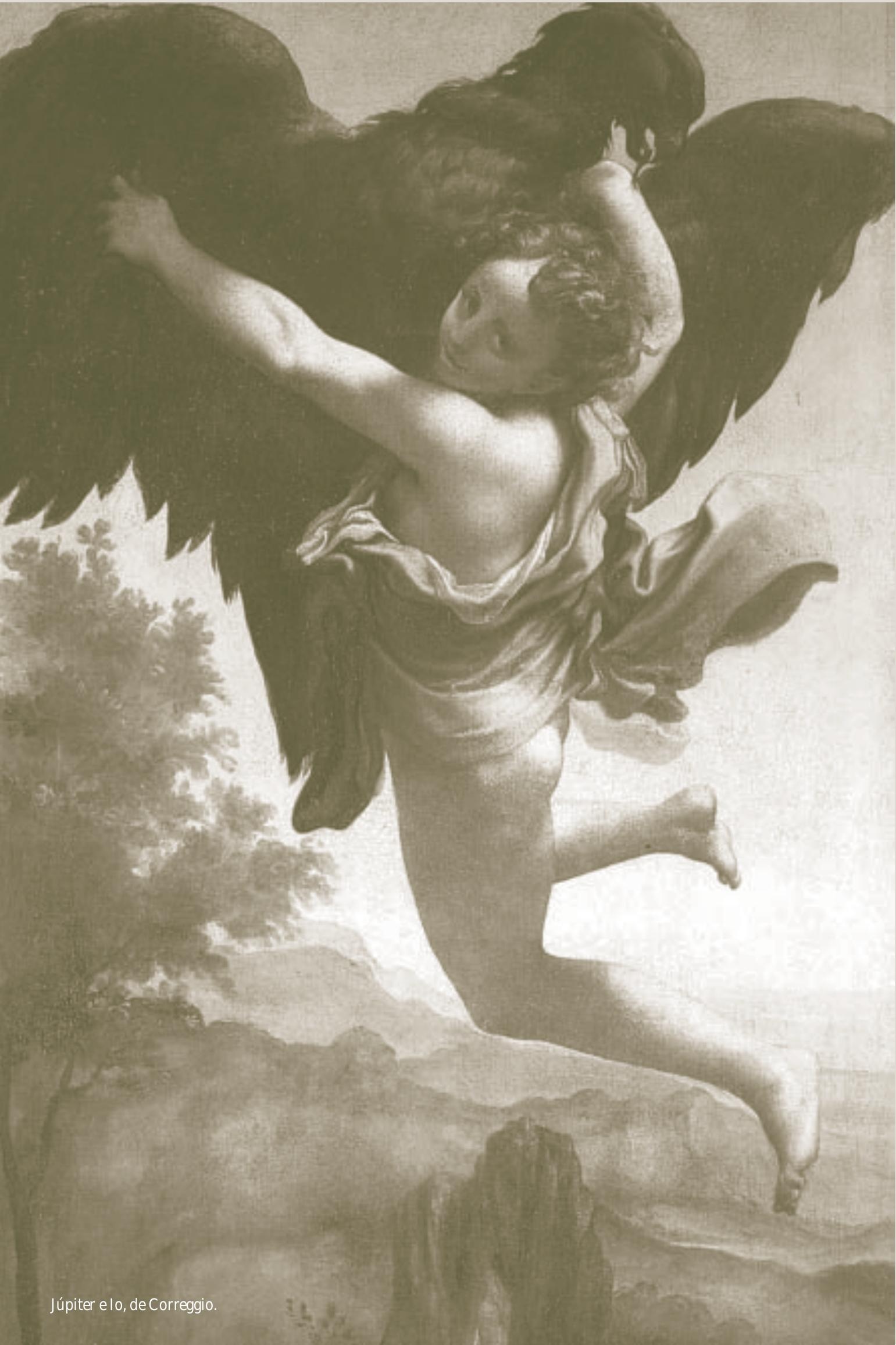


Como fuere, en Occidente, a partir de estos comienzos en Grecia antigua, el mito religioso en general no desapareció, sino que pasó por diversos momentos, o mejor dicho, los relatos fueron siendo diferentes: tomó ropaje cristiano - a ratos de hechura nueva pero de tela antigua- , se hizo compatible con esquemas racionales en la teología y, en fin, moldeó la visión del mundo por algunos siglos, hasta el resquebrajamiento de la Epoca Moderna. Lo curioso de este proceso es que los diversos relatos míticos que se fueron sucediendo juzgaron a los otros como cosa falsa: el rechazo al paganismo por parte de los padres de la I glesia; la consolidación del dogma y la expurgación de lo apócrifo en los primeros siglos del cristianismo; las sucesivas condenas a las también sucesivas herejías por parte de la I glesia oficial; las guerras religiosas cuando la ruptura dela Reforma, son aspectos de aqueIlo. Es decir, se consideraba, desdela narración sentida como verdadera, que las otras eran falsas. Pero esto, el desconocer la raigambre mítica de la propia "verdad", no fue asunto privativo de los relatos formalmente religiosos, sino que se manifestó también en los esquemas "racionalistas" del pensar, también ya desde la Antigüedad en adelante, en un proceso que llega hasta nuestros días. Y es también interesante constatar que en las propuestas expresamente laicas sobre el hombre y el mundo late subyacente la raíz religiosa de las primeras explicaciones intuidas por la humanidad; así por ejemplo, cuando la idea de progreso toma forma a fines del siglo XVIII, particularmente en Condorcet, ¿no es acaso el viejo afán de retorno al Paraíso, lo queallí se hace presente, y en especial una laicización de la idea cristiana del mismo?Y, sin embargo, losilustrados que contribuyeron al proceso abominaban, en su mayoría, del cristianismo, denunciándolo como conjura perversa para mantener a la humanidad en la oscuridad de la superstición, y así hacer más fácil su dominio. Ciertamente se afirmaban en otro gran mito que renacía: el de la igualdad de los hombres, entendida (sentida) como si fuese algo dado por naturaleza, cuando en el origen de la creencia estaba, laicizado, el relato sobre un origen común de manos de un Dios Padre, lo que volvía a todos hermanos...

En todo caso, encontramos otro punto a aclarar: los grandes mitos en acción en la historia no parecen ser meramente producto de un afán de dominio (aunque el mito que en un momento dado se impone, domina en tanto fija una concepción del mundo y del hombre), sino que concitan la adhesión del que acepta su verdad porque le otorgan un fundamento a su vivir. Y esto más allá de los mitos religiosos. A hora bien, ¿qué es lo que puede concitar esa adhesión en un mito? ¿La historia que cuenta? ¿El contenido simbólico que encierra? Q uizá en parte, pero el mito -el mito vigente- no es simplemente el relato ni su contenido simbólico, sino lo que más allá de éstos permite ser vivido, dando sentido a ese vivir. Dicho de otro modo: un mito quetenga vigencia integra al individuo que deél participa en una cons- 
telación de creencias, que le proporciona los puntos de referencia necesarios como para que la vida tenga sentido, ubicándose en relación a ellos.

No obstante, lo anterior no descarta el hecho de que, también desde la Grecia clásica, se advirtió el poder del mito en la articulación de los asuntos humanos, y cómo dichos asuntos - por ejemplo, el comportamiento político- podían ser encauzados en la dirección considerada conveniente, por medio de la utilización adecuada de mitos ad hoc. Toda la discusión que encontramos en la República de Platón sobre el actuar de los poetas y la necesidad de reemplazar la imagen vigente de los dioses que aquéllos habían otrora elaborado por una nueva, inventada a tal efecto, es buena muestra de dicha consideración.

Pero conviene aclarar ahora, que no sólo en los mitos de tipo religioso encuentra el ser humano un fundamento quele ayude a saber a qué atenerse; todo tipo de mitos, en general, provee de dicho auxilio: sagas heroicas, relatos normativos (sobre el proceder en sentido amplio), gestas anteriores de la sociedad presente, etc., complementan el conjunto.

Por otra parte, no sólo lo que podemos llamar "grandes mitos" - religiosos, ideológicos, soteriológicos en sentido lato, etc.- cumplen una función de sustentación; también lo hacen aquéllos de tono menor que ocupan, en determinadas épocas históricas, el lugar dejado por el repliegue delos otros. Sucedeque, en al gunos momentos, ciertos mitos experimentan una pérdida de sentido, dejan de "hablar" a los hombres, no son "sentidos" por éstos, y pasan a ser relegados al nivel de "fábulas". Cuando esto ocurre, los elementos míticos de la trama de fondo de una cultura dada son sustituidos por otros, muchas veces de desleído espesor. En palabras deCencillo (escritas en 1970): "Cuando en una sociedad pluralista o en un determinado momento histórico dejan de presentarse mitos colectivos o nacionales, o estos mitos se reducen a ser el "país de la libertad", pasan a ejercer la función aglutinante de aquellos mitos una serie de figuras y de realidades más modestas, pero con el mismo poder de sugestión: determinadas estrellas de cine o del de porte 0 determinadas clases de hombres 0 de profesiones [...]. Por muy modesto que sea el valor de estos mitos y por muy escaso que resulte su contenido filosófico, no cabe duda de que a falta de otros mitos, cuando el horizonte de las creencias ha quedado desmantelado por el escepticismo y el positivismo industrial y comercial, estos mitos, por desgracia también comerciales, vienen a llenar el vacío inmenso que dejaron otros cuya función no podía quedar sin ejercicio"7. La función de éstos-como ya dije- es la misma cumplida por los anteriores, aunque su consistencia pueda ser menguada: para muchos de los que se sienten al margen de los puntos de referencia vigentes, la trayectoria mitificada de un artista, por ejemplo, pue-

${ }^{7}$ Cencillo R., Luis, M ito. Semántica y realidad, B.A.C., Madrid, 1970, p. 13. 


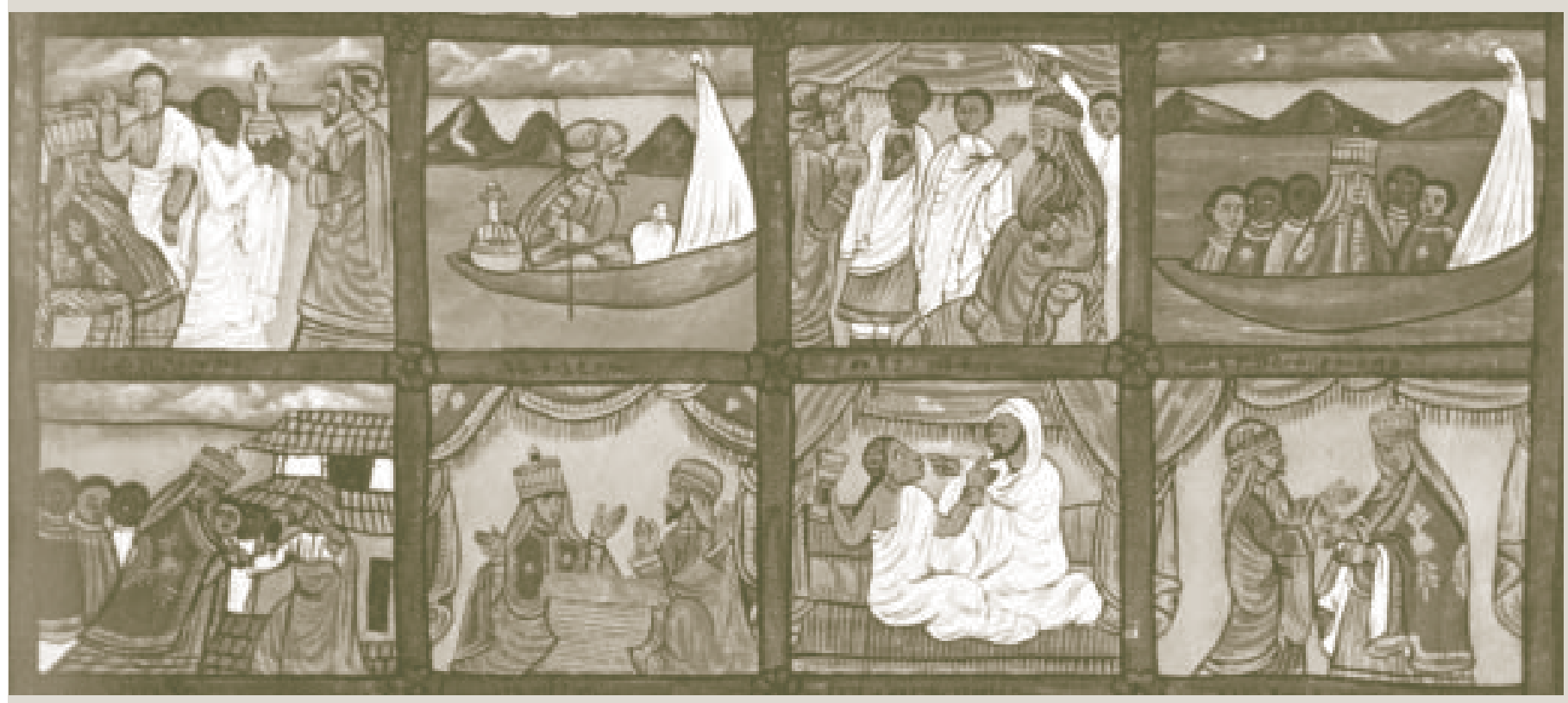

Arriba, un emisario de la reina de Saba navega junto a las pirámides hacia la corte del rey Salomón y al que seguirá después la reina; abajo, está representado el encuentro entre los dos monarcas. Salomón seduce a la reina; más tarde ella regresa a su país y da a luz un hijo. Cuando éste fue mayor, visitó a Salomón, estudió la fe hebrea y fue ungido rey de Etiopía. La historia está narrada en el Kebra Nagast, libro compilado por el monje Yesac en el siglo XIV para servir de fundamento a la pretensión del reino de Etiopía de ser el verdadero sucesor de Israel.

de ser el arquetipo salvador frente a la banalidad cotidiana, una categoría a la cual asimilarse, ganando así la vida del sujeto un sentido, aunque pueda parecernos mínimo visto desde afuera: quizá unas mechas a lo iroqués teñidas de rojo, tal vez cierta vestimenta oscura... Y en estepunto, es muy probablequeel estilo nosilustre sobreel mito queestá detrás: cierto aliño de éxito "wallestritesco" puede revelarnos también otro arquetipo, llegado el caso.

Con todo, los mitos están también expuestos al transcurso del tiempo, y van cambiando - a veces para sobrevivir frente a mitos dominantes- hasta llegar a ser difícilmente reconocibles: para dar un ejemplo, consideremos las perlas (como propone M ircea Eliade), que son preciadas entre nosotros por representar un cierto status económico, en lo que sería un disfraz de su simbolismo mágico arcaico de "buena medicina" en tanto símbolos de la vida por proceder del interior de las conchas, las queeran, a su vez, símbolos del poder generatriz femenino... ${ }^{8}$. En otras ocasiones, bajo arquetipos máso menos banales subyacen -ignorados muchas veces por quienes los adoptan como propios- referencias a mitos más fuertes y principales: así es posible, en otro ejemplo, que quien ande con una melena a lo rastafari, emulando a Bob M arley, ignore la filiación mítica que lo vincula, a través de la figura de Hailie Selassie, con la pareja mítica fundadora de Salomón y la reina de Saba, de quienes los soberanos etíopes se proclamaron, por siglos, descendientes... Todos estos procesos de enmascaramiento vuelven interesante el rastreo de mitos concretos.

${ }^{8}$ Eliade, M., Imágenes y símbolos, Taurus, M adrid, 1979, pp. 139-142. 
Lo anterior nos remite a otro punto: el de que, en ausencia de grandes mitos, conviven en la sociedad -en la nuestra, por ejemplo- mitos diversos en un conjunto polivalente, que abarca a sectores diversos, según estratos sociales, nivel de instrucción, edad, afinidad ideológica, sensibilidad estéti$\mathrm{ca}$, etc. Es decir, pareciera que en nuestro país no tenemos vigentes grandes mitos "transversales", sino propuestas arquetípicas fragmentarias. Y esto obliga a preguntarse en qué fondo cultural se afinca nuestra sociedad. ¿Tenemos hoy arquetipos que nos aglutinen o sólo tenemos como base un abigarrado conjunto de relatos en precaria unión? La pregunta, en estos tiempos de globalización, tiene - me parece- cierta importancia.

La globalización misma podemos entenderla como el intento de introducir básicamente un par de mitos fundacionales: el de la democracia en lo político y el del mercado en la economía. Pero, ¿en quésentido puededecirse que sean mitos?: en tanto se pretende que el mensaje actúe directamente, que sea sentido más que racionalizado por el receptor. Y como los mitos se internalizan con ritos ${ }^{9}$, en estecaso los ritos son las elecciones y el consumo. Se supone entonces que al poder ejercer uno y otro, el individuo debería sentirse dueño de sí, en posesión del sentido de su vida como nunca antes en la historia de Occidente. Al menos, eso parece alentar en el espíritu de quienes formulan la propuesta ${ }^{10}$.

Y vemos, sin embargo, queello no logra cuajar como sedimento fundante ni siquiera en lo quellamamos "O ccidente", en general. Además, desde otras culturas le surgen adversarios fundamentados en sus propios mitos de fuerteraigambre. "Bueno - dirán algunos-, pero esosotros mitos, como por ejemplo los quecimentan losfundamentalismos religiosos, son malos, y estos otros no". Si es así, entramos a otro terreno. ¿Cómo juzgar de la posible "bondad" o "maldad" de los mitos? Supongo que desde nuestra perspectiva de valores. Pero ésta, ¿no tiene, también, fundamentos míticos en última instancia? Sí, por cierto. ¿Qué cabe, entonces? Tal vez, volver, más o menos, al viejo esfuerzo ya comenzado por los griegos: tomar frente a ellos distancia desde la racionalidad, pero no desde la racionalidad "kantiana" - que sería la única posibilidad realmente autónoma, si pudiera darse-, sino simplemente desde la racionalidad que descubre su mestiza raíz, esto es, la racionalidad que descubrequesu accionar no es aséptico, aquella racionalidad quese da cuenta de que lo que estima como verdad en las cosas humanas no es simplemente el resultado de juicios apodícticos, sino de la aceptación de aquello que, finalmente, creemos es verdad. Lo que implica aceptar que necesitamos del mito, también. Estimo que es desde una visión semejante, consciente de su propia fragilidad, en donde se puede, si sequiere, basar una tolerancia -hasta

${ }^{9} \mathrm{Cf} .:$ Cassirer, E., op. cit., p. 336.

10Pienso en Fukuyama. También en Rawls. 
donde ésta es posible- frente a otras concepciones del mundo. Aceptar otra cosa es aceptar gato por liebre.

Con esto presente, puede valer la pena el difícil intento de examinar los distintos mitos que articulan la trama un tanto desgarrada que constituye nuestra cultura nacional (o lo que pueda ser llamado así). Pero eso es ya otro asunto.

\section{REFERENCIAS}

Cassirer, Ernst. 1982. El mito del Estado, Fondo de Cultura Económica, M éxico.

Cencillo R., Luis. 1970. M ito. Semántica y realidad, B.A.C., M adrid.

Cencillo, Luis. 1971. Tratado de la intimidad y de los saberes, Sintagma, M adrid.

Eliade, M ircea. 1973. M ito y realidad, Guadarrama, M adrid.

Eliade, M ircea. 1979. Imágenes y símbolos, Taurus, M adrid.

Vico, Giambattista. 1971. "Scienza nuova”, en O perefil osofiche, Sansoni Ed., Firenze. 
